\title{
ТЕОРИЯ
}

\section{НОВАЯ ВЛАСТЬ И ПОЛИТИКА ПОСТКРИЗИСНОГО РАЗВИТИЯ}

\author{
Фадда C.*
}

В статье рассматривается состояние экономической политики, институтов и демократии в период кризиса. Особое внимание уделяется проблемам национальных государств, вынужденных действовать в условиях глобального рынка. Подчеркивая, что современная структура глобального экономического управления неэффективна, автор указывает на резкое несоответствие между потенииалом международных институтов и необходимостью эффективного глобального управления. В этой связи исследуется структура, а также предель управления Европейским союзом и обсуждается идея создания Соединенных Штатов Европь.

Ключевые слова: политика, глобализация, национальное государство, глобальный рынок, глобальное управление, Европейский союз, сетевое управление.

The article discusses the status of economic policy, institutions and democracy in times of crisis. Special attention is paid to the problems of nation States, forced to act in the global market. Stressing that the current structure of global economic governance is ineffective, the author points to the sharp discrepancy between the capacity of the international institutions and the need for effective global governance. In this regard, studies the structure and limits of control of the European Union and discussed the idea of creating a United States of Europe.

Keywords: policy, globalization, national state, global market, global management, European Union, network management.

Глобализацию как природную, так и историческую нельзя сравнивать с чем-то неизбежным или неотвратимым. Подавляющее большинство движущих сил глобализации тесно связаны и мотивированы интересами как частными, так и общественными, которые в любом случае следует учитывать [Smith, Naìm 2000: xiv].

Однако если имеют место ошибочные экономические меры, следует брать во внимание интересы отдельных групп, которые так или иначе извлекают выгоды из этих решений [Caffè 1986: 42].

\footnotetext{
* Фадда Себастьяно - профессор департамента экономики Римского университета. E-mail: sebastiano.fadda@uniroma3.it.
} 


\section{1. Введение}

Какими бы ни были технические аспекты изменившихся и развивающихся отношений между национальными государствами и глобальными рынками, каковы бы ни были трудности со сложной глобальной сетью финансовых потоков, сама причина, по которой представляется невозможным создать эффективную структуру экономического управления как на европейском уровне, так и на глобальном, заключается в широко распространенном мнении о том, что макроэкономическая политика вообще (не говоря уже о промышленной политике) не представляет ценности сейчас (и не будет использована в будущем), поскольку все рынки сами по себе, без какого-либо вмешательства в политику могут эффективно работать и обеспечивать эффективное распределение ресурсов и высокие экономические показатели.

Однако менее резко эта точка зрения выражена в сфере национальной экономики, где некоторые меры данной политики (в разной степени в разных государствах) по-прежнему разрабатываются и внедряются, но в большей степени она развертывается на международном уровне, создавая систему, которая допускает сосуществование своего рода иерархического экономического управления внутри государств и своего рода анархического отсутствия управления (можно сказать, идеальный свободный рынок) в их внешних отношениях и трансграничных сделках.

Если бы мы придерживались этой точки зрения, было бы бессмысленно рассуждать на тему глобального экономического управления или соответствующих демократических международных экономических институтов. Было бы также бессмысленно обсуждать, включать или исключать такие цели, как полная занятость, справедливое распределение доходов или даже экономический рост. Абсолютное «невмешательство», абсолютное дерегулирование, абсолютная приватизация и сокращение государственных расходов (особенно для социальных услуг и общественно необходимых товаров) были бы единственными объектами экономической политики, достаточными для обеспечения сбалансированного государственного бюджета (который, как ни странно, кажется, стал целью - если не сказать единственной целью, - а не инструментом экономической политики) и контроля инфляции: ничто более не должно входить в сферу экономической политики.

Однако кризис 2008 г. и следующий за ним доказали, что это не так и что именно ущербность правил (особенно на финансовых рынках), отсутствие соответствующих международных экономических институтов лежат в основе процесса, который превратился в один из самых суровых кризисов и спадов прошлого века, в конечном итоге побуждая сами рынки, компании и банки просить о помощи со стороны центральных банков и государственных органов. Уже не имеет смысла настаивать на игнорировании этого факта и ожидать преодоления кризиса, не сталкиваясь с проблемой соответствующих институтов для глобального экономического управления, особенно для европейского управления. Поэтому стоит рассмотреть эти проблемы, с тем чтобы изучить основные вопросы и их возможные решения, отвергая ложную точку зрения о том, что наилучшая экономическая политика не должна иметь никакой политики вообще, а также отвергать еще более плохую стратегию принятия мер по защите финансовой, политической и монополистической ренты ценой уничтожения реальной экономики, которая якобы является свободным рынком. Но нам хорошо известно, что за нерешительностью и непреодолимыми трудностями при рассмотрении соответствующих ре- 
шений по-прежнему стоит влияние старой идеи абсолютного невмешательства. На самом деле, как считал Дж. Кейнс, проблема часто не в том, чтобы принимать новые идеи, а в том, чтобы избавиться от старых.

\section{2. Национальные государства против глобальных рынков}

В самом начале «конфликт» между рынками и государствами зародился, когда уровни состояния и масштабов рынка стали значительно отличаться. Поскольку технологии обработки информации, телекоммуникационные сети и сниженные транспортные издержки достигли значительных уровней, были созданы условия рыночных (и особенно финансовых) потоков для принятия ими глобального характера. Однако следует понимать, что это были необходимые, но недостаточные условия для возникновения глобальных рынков: фактически национальные правительства сделали намеренный выбор в пользу отмены границ, ограничений и правил, регулирующих движение товаров и капиталов, и это было определяющим фактором появления глобализации в сфере экономики. Там, где национальные правительства не были так уверены (как миссис Тэтчер, Рональд Рейган и Казначейство США) или проявили нежелание в отношении дерегулирования, приватизации и либерализации, Международный валютный фонд использовал свое оружие, чтобы убедить их.

На этом этапе сеть глобальных взаимосвязей между действующими в мире агентами ожила с двумя характеристиками: объем транзакций (в частности, финансовых операций) стал непомерным даже по сравнению с объемом бюджетов национальных государств, а измененный баланс сил между глобальными субъектами сделал любую возможную регулятивную деятельность национальных государств чрезвычайно сложной и, как правило, неэффективной [Cooper 2003]. Национальные границы становятся просто неактуальными, когда сеть трансграничных транзакций происходит за пределами государственного контроля над трансграничными транзакциями в старом понимании, и даже без ведома государства. Очевидно, что для обеспечения эффективности в этих условиях вся нормативная деятельность должна быть перенесена на международный или глобальный уровень. Однако отсюда вытекают две проблемы: первая - это внутренняя эффективность и эффективность международных регулирующих органов или организаций, а вторая - их совместимость с суверенитетом отдельных национальных государств. И если предположить, что между эффективностью регулирующей деятельности международных органов и суверенитетом национальных государств подразумевается обратная взаимосвязь, возникает серьезная дилемма, выходящая на первый план. Это особенно заметно в случае Европейского союза. Если национальный суверенитет будет сохранен - формально, в том, что касается регулирования финансовых рынков и других сфер экономической политики, то его деятельность будет в значительной степени бесполезна и неэффективна; если, с другой стороны, он сокращается в пользу власти международных, например европейских, органов, то возникает проблема демократии.

С этой точки зрения трудно разглядеть, по мнению М. Кастелла, прогрессивную эрозию суверенитета национальных государств посредством наднациональных институтов, с одной стороны, и региональных или местных институтов с другой, как намеренное обращение к «сетевому государству», чтобы сохранить свою роль и свою силу [Castell 2000]. Кажется более разумным рассматривать эти процессы как прогрессивную «капитуляцию» национальных государств в пользу 
глобализации, а также децентрализацию и передачу полномочий. Тем не менее следует ли считать, что интернационализация производственного процесса и транснационализация финансовых рынков являются «естественными» явлениями, независимыми от выбора национальных государств, - это, по моему мнению, открытый вопрос. Несомненно, возникает несогласованность между силой, которую все еще демонстрируют крупные национальные государства в проведении своей собственной экономической политики (с одной стороны, США, Великобритания и Германия, а с другой - Китай, Индия и Бразилия), что подрывает стабильность международной системы постнационального управления, и либерализацией, а также глобализацией рынков, для которых необходима такая глобальная организация управления.

\section{3. Глобальное правительство: эффективность и демократичность}

Нынешняя структура глобального экономического управления далека от адекватной и не слишком эффективна - управление Европейским союзом, в котором противоречие между денежной унификацией и единым рынком, с одной стороны, и сохранением суверенных национальных государств - с другой, особенно остро. Фактически международный этап демонстрирует резкое несоответствие между потенциалом международных институтов и необходимостью эффективного глобального управления. Нынешняя ситуация характеризуется наличием множества участников; некоторые из них формальные, некоторые - неофициальные.

Среди формальных мы можем отметить на глобальном уровне те международные организации, которые отвечают за нормативную деятельность в силу официальных соглашений между государствами. Отметим самые важные: ООН, МВФ, ВТО и Всемирный банк со всеми их агентствами. Неофициальными субъектами могут считаться те, которые, хотя и не назначены для какой-либо регламентационной деятельности, тем не менее могут влиять на поведение экономических акторов и государств на мировой арене посредством отдельных действий либо посредством взаимосвязанных альянсов с другими субъектами. К ним можно отнести крупные корпорации, инвестиционные банки, рейтинговые агентства, неправительственные организации, социальные движения, политические сети и т. д., а также неофициальные соглашения между некоторыми из субъектов, которые фактически являются частью официальных международных организаций.

В отношении этих учреждений могут быть подняты два вопроса: первый связан с их эффективностью, второй вопрос - о демократии. Низкая степень эффективности в основном сопряжена с отсутствием сотрудничества между национальными государствами. Что касается прозрачности и открытости, то в отношении конкуренции и политики регулирования трудности в поиске противоречащих друг другу интересов отдельных государств часто препятствуют принятию эффективных решений. Что же касается Международного валютного фонда, решения которого, напротив, всегда были далеки от неэффективности, представляется разумным поделиться известным взглядом Джозефа Стиглица [Stiglitz 2003], что склонность фонда навязывать неправильную политику (то есть в целом требовать рецессионную политику в обмен на помощь, а не предоставлять странам кредит, необходимый для предотвращения рецессии) в основном обусловлена, с одной стороны, принципом голосования, когда отдельные государства оказываются в неравных условиях (например, члены и не члены G7), а с другой - ее составом, который ограничен министрами финансов и руководителями центральных банков. 
Вопрос о демократичности нынешней международной системы управления осложняется проблемой определения. Чтобы упростить эту проблему, два основных принципа можно рассматривать как фундаментальные компоненты демократии. Во-первых, участие людей, которые затрагиваются коллективными обязательными решениями в процессе принятия этих самых решений. Во-вторых, дееспособность политиков и их ответственность связаны с эффективностью процедур их возможной замены. Понятно, что ни одно официальное или неофициальное международное учреждение, упомянутое выше, не может считаться демократичным по этим двум критериям. И поскольку демократия является признанной доброй волей, распространяющейся по всему миру, международные институты, которые не отвечают этим требованиям, страдают от своей репутации и могут потерять легитимность. Вероятно, можно найти какое-то сетевое или интерактивное управление, но я вернусь к этой теме позже, обратив особое внимание на Европейский союз.

\section{4. Европейский вариант борьбы в кризисной ситуации}

Более пристальный взгляд на структуру управления Европейского союза показывает аналогичную кооперацию официальных и неформальных институтов. Но прежде чем исследовать институциональную структуру, стоит рассмотреть содержание политических мер, принятых на европейском уровне, чтобы справиться с нынешним финансово-экономическим кризисом. Впоследствии мы сможем увидеть, откуда взялся этот пакет и мог ли быть представлен другой пакет в соответствии с нынешним составом руководства. Если это станет невозможным, в срочном порядке возникнет сильная потребность в новом управлении.

Суть европейской экономической политики в отношении так называемого кризиса суверенного долга можно резюмировать следующим образом. Во-первых, наличие Европейского центрального банка для спасения национальных банков в трудных условиях. Банки могут использовать (и использовали) эту инъекцию ликвидности для покупки облигаций, представляющих государственный долг стран, рейтинг которых был понижен соответствующими агентствами. Следует понимать, что Европейский центральный банк, в отличие от других центральных банков, покупает государственный долг на первичном рынке. Но этот способ финансирования государственного долга посредством ликвидности, предоставляемый коммерческим банкам, создает своеобразный эффект, который проявляется как финансирование спекулянтов на финансовых рынках. Фактически, таким образом, средства ЕЦБ используются для оплаты облигаций по цене, определяемой нормой прибыли, установленной спекуляцией, вместо того чтобы использоваться для наложения ограничения на прирост процентной ставки казначейских облигаций по спекулятивным атакам. С другой стороны, по конституции миссия ЕЦБ не включает в себя содействие экономическому росту и поддержанию полной занятости, она ограничивается только поддержанием денежной стабильности, которая обычно интерпретируется лишь как предотвращение инфляции.

Во-вторых, предоставление кредитов странам, которым грозит дефолт, через схему «Европейская система финансовой стабильности» и ESM (Европейский механизм стабильности). Эти положения, как правило, были слишком запоздалыми и слишком недостаточными в отношении неотложных потребностей стран, подверженных риску дефолта, чтобы избежать рецессии. Тем не менее было мудрым решением, вопреки позиции Германии, не привлекать Международный ва- 
лютный фонд к этим операциям, поставив перед Европейским союзом задачу справиться по своим критериям с дисбалансом своих государств-членов.

В-третьих, наложение строгих фискальных правил через «Финансовый договор» для всех государств-членов. Эта мера поднимает старую мифическую ценность в $60 \%$ как максимально разрешенный процент государственного долга к ВВП, привлекая все государства-члены к ликвидации в течение 20 лет долга, превышающего эту стоимость, независимо от того, каковы экономические условия и позиции конкретной страны в деловом цикле. Это приводит к некоторому ограничению, которое должно быть реализовано за счет сокращения государственных расходов и увеличения налогообложения. Пик такого подхода достигается с требованием (оперативно осуществляемым Италией) включать в конституцию каждого государства-члена правило сбалансированного государственного бюджета (такое правило не применяется к отдельным государствам в любом другом федеральном государстве мира). Очевидно, что эти правила противоречат возможности реализации контрциклической макроэкономической политики и усугубляют рецессию в странах, которые уже испытывают трудности, что ставит под угрозу это же стремление к сокращению соотношения государственного долга и ВВП, которое было первоначальной целью этих решений. Правило сбалансированного государственного бюджета, в частности, обязано действовать как «механизм автоматической дестабилизации» с проциклическими последствиями, оно экономически лишает власти фундаментального инструмента для управления макроэкономическим спросом. Верно, что «фискальный подход» допускает циклические эффекты и единичные меры, которые не будут приняты во внимание, но это неопределенное и недостаточно сильное решение, чтобы избежать дестабилизирующего эффекта.

Параллельно с этими принятыми мерами первостепенное значение имеют «упущенные возможности», которые рассматриваются здесь как те, которые могли бы использовать разумные экономические полномочия эффективно управляемой страны.

1. Первый пример «упущенных возможностей» - финансовое регулирование, в сфере которого не были применены все необходимые и возможные меры. Создание СРВ и трех сопутствующих ему агентств - недостаточно эффективный инструмент, учитывая их структуру и масштабы. Финансовые рынки в этом случае остались нетронутыми, сохранив неограниченную свободу в операциях с деривативами, ненормированную активность операций на нерегулируемых рынках (транзакции ОТС составляют около $90 \%$ от общего числа), странные (непонятные, загадочные) отношения с рейтинговыми агентствами, извращенное смешение коммерческих и инвестиционных банков - и все это при отсутствии какоголибо налога на финансовые операции.

2. Вторым явлением «упущенных возможностей» стало оказание поддержки роста государств - членов союза, находящихся в трудной ситуации. Для того чтобы избежать рецессии и остановить разрастающийся кризис (который также негативно сказывается на так называемом «рыночном доверии», на стабильности валютного союза и европейской валюты в целом), следовало разрешить последовательные перемещения ресурсов из европейского бюджета (до смешного маленьких объемов сегодня - около 116 млрд евро) либо в виде обновленного экстренного «плана Маршалла», либо путем обычного вмешательства в стратегию роста. Ничего подобного, к сожалению, сделано не было. Так называемые «евро- 
связи» можно считать слабым первым шагом в этом направлении, но сама идея остается смутной, полной неопределенностей и в любом случае все еще не воплощенной в жизнь.

3. Третья сфера «упущенных возможностей» - стратегии роста. Кажется, будто экономический рост больше не является основной целью европейской экономической политики. Это направление совершенно точно исчезло из программы задач ЕЦБ, а его присутствие в амбициозных программах наподобие «Европы 2020» является, по большому счету, символичным. В этой программе особым образом выделяется то, что правила никоим образом не налагаются на государства члены соглашения, а принятие решений о том, как и в какой мере им следовать, остается за последними. На самом деле не существует ни макроэкономической политики для поддержки роста, ни реальной политики в поддержку инноваций, индустриального развития, энергетики, социального обеспечения, производственных отношений и прочего. Единственным направлением европейской политики, которое может быть отнесено к этой сфере, является аграрное, зачастую подвергающееся жесткой критике.

4. Последнее упущение заключается в том, что на сегодняшний день в Европе не существует ни единой фискальной политики, ни согласования налоговых режимов. Единая фискальная политика должна быть осмотрительной и подверженной корректировкам в соответствии с циклическими колебаниями в экономике, также она должна согласовываться с единой денежной политикой. В реальности ситуация противоположная: у нас есть набор строгих, жестких «фискальных правил», опирающихся на произвольные параметры, которые предполагается применять автоматически к любой стране независимо от специфичности ее ситуации, а определение санкций передано в руки «технократов», можно даже сказать, «бюрократов». Это очевидное нарушение двух фундаментальных принципов - принципа целесообразности использования фискальной политики как инструмента для достижения целей экономической политики и принципа «нет налогам без представительства».

\section{5. Экономическое управление ЕС}

Теперь мы должны спросить: откуда исходят подобные направления «европейской экономической политики»? Какое из европейских правительств предложило использование такого подхода? На что вообще похоже сегодняшнее экономическое управление?

Первое, что следует упомянуть в связи с этим, - полная отстраненность от этих решений как Европейского парламента, так и исполнительного органа Европейского союза, Европейской комиссии. Другими словами, фундаментальные органы демократии ЕС не играют значительной роли в процессе принятия им решений и не признают те правила и политику, которые в идеале должны быть учтены. Таким образом, ЕС не может никоим образом считаться федеративным государством, эволюция европейского правительства далека даже от движения к этой модели.

Процесс принятия решений, функционировавший в Европейском союзе, принадлежит скорее к категории международного сотрудничества и международных соглашений, ведь на самом деле органы, задействованные в этом процессе в большей степени, - это Европейский совет и Еврогруппа. Первый состоит из глав государств или правительств стран - участников ЕС, председателя Европейской 
комиссии и избранного председателя самого Европейского совета; начиная с 1 декабря 2009 г. (Лиссабонский договор) в его обязанности входит «определение основных приоритетов и направлений политики Европейского союза». Второй орган включает министров финансов государств - членов ЕС, которые ввели в оборот евро; он обычно созывается за день до собрания Совета по экономическим и финансовым вопросам (ЭКОФИН), который, в свою очередь, является структурой, созданной Советом Европейского союза для рассмотрения вопросов бюджета и государственных финансов (хотя по вопросам, касающимся евро, в голосовании принимают участие только министры Еврозоны). Важно понимать, что оба этих органа (уточню: Европейский совет и Еврогруппа, ведь читатели уже могли забыть, какие именно органы, их в этих трех предложениях не счесть), пусть и принимавшие активное участие в разработке экономической политики Европейского союза, фактически были неформальными до 1 декабря 2009 г., формализовавшись лишь с принятием Лиссабонского договора; поэтому сейчас, хотя их существование официально подтверждено, они все еще не имеют формальной законодательной власти. Несмотря на это, они являются наиболее влиятельными структурами в определении направлений европейской экономической политики.

Однако это не отражает в полной мере реальную структуру экономического управления ЕС. Известно еще несколько неформальных образований, которые оказывают значительное влияние на формирование направлений экономической политики (в частности, связанных с вопросами преодоления кризиса). Первый в этом списке - Европейский центральный банк, абсолютно независимый и неподотчетный никаким другим учреждениям, несмотря на потенциальное слабое воздействие со стороны Еврогруппы. Второе образование составлено путем неформальных соглашений между ограниченным количеством государств (это, как правило, Германия и второстепенный временный партнер). Третье - так называемая «Тройка» - включает в себя Европейский центральный банк, Международный валютный фонд и председателя Европейской комиссии. Следует отметить, что каждое из этих образований учреждено официально, неформальной является власть, которой они себя наделили. Наконец, существует еще один неформальный институт, действующий как влиятельная международная структура, но, несмотря на свой сверхъевропейский масштаб, имеющий значительное влияние в сфере европейской экономической политики, - Форум по вопросам финансовой стабильности. Это своего рода клуб центральных банков, правительств, регулирующих органов и других международных организаций, возникший в 1998 г. после российского экономического кризиса в поддержку «Большой семерки» и увеличивающий влияние относительно последующих «Большой восьмерки» и «Большой десятки».

Конечно, неправильным будет считать, что все участники вышеперечисленных неформальных структур управления также являются неформальными (к примеру, Ангела Меркель или Марио Драги); что не определено официально, так это власть, которую они имеют, и влияние, которое они используют в процессе принятия решений в Европейском союзе. На самом деле этот процесс можно описать как нечто, зарождающееся на нижнем уровне «формальности», эволюционирующее впоследствии в формальные институты, обладающие законодательной властью. Тем не менее не все решения экономической политики достигают высшего законодательного уровня. Договоры, соглашения между государствами (такие как Пакт стабильности роста или Бюджетный пакт) и другие решения часто минуют подобные законодательные уровни ЕС: будучи выражением сотрудничества меж- 
национальных структур, они незамедлительно проходят в «технические» и бюрократические органы для реализации.

\section{6. Пределы европейского экономического управления}

Таким образом, у нас есть, с одной стороны, комплекс мер экономической политики, а с другой - понимание, в результате какого процесса и какой институциональной управленческой структурой он был порожден. Содержание этой политики явно необоснованно с точки зрения экономической теории и представляется очевидно дестабилизирующим и рецессионным. Тривиальная реакция ждать и наблюдать за долговременными последствиями - подкрепляет это суждение с течением времени. Разве что это («долгое время») должно продолжаться до того момента, пока мы не умрем. Процесс принятия решений в этой сфере нельзя назвать демократическим по двум уже названным причинам - недостаточное участие и недостаточная подотчетность. Более того, как в формальных, так и в неформальных процедурах раскрываются некоторые ее признаки, имеющие особо важное значение. Первый из них - доминирующее присутствие министров финансов и Европейского центрального банка у истоков принятия экономических решений; никакие другие министры или другие сферы, такие как труд, промышленность или преобразования, не имеют такого же пространства и такой же силы слова. Вторым качеством является доминирующая роль национальных государств. Страны-участницы не желают передавать власть европейским демократическим институтам; они предпочитают решать фундаментальные задачи путем межнациональных сделок, альянсов и соглашений, в то же время пытаясь уменьшить количество вопросов, находящихся в ведении европейского уровня. На основании этого можно заключить, что хорошее финансовое состояние и мощь более влиятельных государств играют важнейшую роль в определении не только направлений европейской экономической политики, но и осуществляемых технических мер.

Не следует ли нам в таком случае сказать, что экономическое управление Европы работает эффективно? Если принимать во внимание стандарт оптимального распределения, критерий снижения транзакционных издержек или любые другие экономические показатели, с помощью которых обычно оценивается состояние экономических институтов, мы, возможно, скажем «нет». Однако они безусловно эффективно справляются с защитой интересов финансовых групп и инвестиционных банков, учитывая политику «нового меркантилизма» некоторых развитых государств.

Эти институты прекрасно подходят для применения мер с использованием высоких процентных ставок по государственному долгу, неважно, насколько пагубно это скажется в результате на секторе реальной экономики, и независимо от нарастания кризиса или роста безработицы. Они также безупречно соответствуют принятию мер, ослабляющих производственный базис некоторых стран, повышая тем самым экспортные перспективы других (по меньшей мере до такой точки, где первые становятся настолько бедными, что существенно снижают объемы импорта) или увеличивая шансы на поглощение ослабленных. Помимо всего прочего, с их помощью можно заменить обесценивание валюты девальвацией конкурентоспособной заработной платы там, где существуют разрывы в производительности, и ликвидировать государство всеобщего благосостояния, назвав эти меры путем выхода из кризиса. Помня о подобном положении дел, стоит упомянуть слова 
лорда Итуэлла: «Институты - это всего лишь учреждения, они не являются признаком эффективных рынков. Если институты препятствуют достижению экономических целей общества, как бы они ни были сформулированы, такие институты должны быть изменены» [Eatwell 2012].

Подводя итог вышесказанному, европейское экономическое управление обречено и дальше придерживаться ошибочных направлений в экономической политике, исходя из того, что финансовые интересы и национальные государства играют ведущую роль в процессе принятия решений. Это, в свою очередь, является прямым следствием того, что Европейский валютный союз представляет собой некий гибрид: это ни федеративное государство, ни международная организация различных государств. Проведение правильной макроэкономической политики (фискальная и денежная) и воплощение стратегий реальной экономики (к лучшему или худшему) возможно будет лишь в рамках единого демократического федеративного государства. В этом случае не будет гарантий реализации правильных стратегий, но они, по крайней мере, станут доступны, тогда как при сегодняшней структуре управления (недостаточно демократичной и небольшой по масштабам) проведение правильной политики весьма маловероятно, если вообще возможно.

\section{7. Навстречу европейскому федеративному государству?}

На самом ли деле модель федеративного государства - это то, к чему приближается сегодня Европейский союз? Более того, возможно ли создание Соединенных Штатов Европы на данном этапе истории?

Что касается первого вопроса, учитывая то, что создание федеративного государства предполагает экономическую и политическую интеграцию, не остается сомнений в том, что усиление националистических движений, стремление сохранить на национальном уровне столь много власти в вопросах социальной и экономической политики, насколько это вообще возможно, увеличение экономического неравенства между странами и углубляющиеся противоречия интересов и союзов среди стран-участниц удерживают ЕС от развития в этом направлении. Безусловно, расширение ЕС путем включения в альянс новых участников сделало прогресс в построении федеративного государства более проблематичным; по этой причине временами возникает идея создания двух Европейских союзов: первый составит основная часть экономически и политически интегрированных стран, а вторым будет большая конфедерация, включающая оставшиеся государства. Этот большой регион станет попросту единым общим рынком (скорее оптимальной рыночной сферой, чем оптимальным валютным пространством), но определенно не политическим объединением. Такое сосуществование частично дублирующих друг друга союзов повлечет за собой, быть может, появление новых противоречий и проблем. Тем не менее факт остается фактом - сегодня Европейский союз кажется стабильным в большей степени как единая рыночная сфера (а не политическое объединение), имеющая своей особенностью единую валюту среди некоторых стран-участниц (но также несущая риск выхода их из Еврозоны) без какой-либо политической интеграции [Eichengreen 2007]. И если мыслить негативно, можно заподозрить, что именно в этом, а не в политически объединенной Европе заинтересованы важнейшие глобальные экономические и финансовые лобби и транснациональные корпорации. 
Более трудным является второй вопрос. Если бы построение политически интегрированного Европейского союза зависело лишь от учреждения надлежащих официальных демократических институтов, таких как наднациональный избираемый парламент или наднациональное избираемое правительство, характеризующееся эффективностью законодательной и административной власти и подотчетностью европейским гражданам, это могло бы стать возможным, стоит только преодолеть сопротивление стран-участниц и обратиться за помощью к опытным и разумным «институциональным проектировщикам». Однако проблема гораздо глубже и сложнее, чем кажется на первый взгляд.

Если принять, что демократические институты представляют собой не просто матрицу парламентских и элективных техник, но сложные отношения с заложенными в них культурой, интересами, идентичностью, историей, общественными ценностями, верованиями и, возможно, языками, что подобные институты выражают свою политическую позицию с помощью различных представителей, тогда возникают сомнения в том, возможно ли вообще на сегодняшний день создание демократического объединенного правительства федеративного Европейского государства [Jachtenfuchs 1997]. Если демократия не может рассматриваться отдельно от всех компонентов общественной жизни, то демократические институты, похоже, могут функционировать только на национальном уровне, где наблюдается достаточная однородность этих компонентов. Несомненно, медленно движущийся исторический процесс возрастания однородности европейских стран может быть ускорен с помощью определенных мер, которые ЕС может предпринять: в этом плане может (и должно) быть полезным даже усиление нынешних официальных демократических институтов ЕС. Но, естественно, параллельно с этим институциональная структура существующей европейской системы сотрудничества в целом должна быть пересмотрена и усовершенствована.

\section{8. Вот оно - решение?}

Как мы могли убедиться, само содержание экономического управления Европейского союза и его демократический характер не оправдывают возложенных на них ожиданий и не соответствуют представлениям об эффективной европейской экономической политике, способной преодолеть кризис и поддерживать экономический рост государств - членов сообщества. Совершенствование экономической политики требует усовершенствования структуры управления. Однако последняя подвергается риску оказаться в ловушке между желаемым, но недостижимым сегодня федеративным устройством и более реалистичным, но не таким эффективным межнациональным сотрудничеством. Поэтому должны быть найдены пути выхода из данной ситуации.

Это очень нелегкая задача, но я смею предположить, что нужные усилия должны быть предприняты одновременно в двух направлениях. Первое направление - изменение приоритетов и задач европейской экономической политики; следует обозначить фундаментальными целями экономический рост, полную занятость, валютную стабильность и сбалансированную внешнюю торговлю. Это требует полной переориентации стратегических мер, как уже было указано в главе 4. Но кто способен стимулировать применение этих мер и реализовать их? Исходя из вышесказанного, явно не нынешняя структура власти. Отсюда следует, что второй целью, на которую нужно направить усилия, является преобразование европейского правительства. 
Это опять-таки весьма трудная задача. Первый возможный путь к ее решению - перенести процесс принятия решений в рамки официальных институциональных органов ЕС - Европейского парламента и Совета Европейского союза. В первую очередь Совет Евросоюза мог бы формировать окончательные решения о содержании европейской экономической политики перед вынесением их на одобрение Европарламента. Эта мера должна будет сопровождаться двумя дальнейшими: во-первых, пересмотром роли ЭКОФИНа в составе Совета Евросоюза в отношении остальных сфер экономической политики и, во-вторых, редакцией некоторых относительно неформальных образований, в частности Еврогруппы: с одной стороны, необходимо придать значимость неформальному сектору, а с другой - нужно расширить структуру этого органа (как и других неформальных институтов), чтобы возможно было включить туда министров других компетенций и представителей гражданского общества, таких как промышленные союзы, профсоюзы, ассоциации потребителей, регионы и т. п. Также должны быть разработаны формальное учреждение этого членства и официальная связь его представителей с Советом Евросоюза.

В работе Совета Европейского союза следует найти баланс в процессе принятия решений: какие вопросы должны обсуждаться на европейском уровне, а какие - остаться в ведении отдельных государств и регионов. В различных вопросах, очевидно, будут наблюдаться различные соотношения, но это все же станет прогрессивным шагом в сторону увеличения роли европейского уровня.

Проблемным полем остается Совет Европы, где влияние национальных государств на сегодняшний день велико и где доминируют наиболее развитые страны. Эта проблема может быть решена путем использования сетевого, или интерактивного, управления, в котором коллективные решения принимаются посредством переговоров, сотрудничества и консенсуса. Однако трудно прийти к сотрудничеству и урегулированию конфликтующих интересов; это подразумевает возникновение нескольких трудностей, с которыми сталкиваются все образования, использующие подход интерактивного управления.

1. Первая проблема связана с хорошо известной «теоремой невозможности». С увеличением числа партнеров (а 27 национальных государств - большая цифра) увеличивается и количество сталкивающихся интересов, и может стать крайне сложно, если вообще возможно, прийти к согласованному решению через механизм голосования. Следовательно, в этом случае «сетевое, или интерактивное, управление» может оказать парализующий эффект на процесс принятия решений и реализацию политики. Это можно преодолеть с помощью переговоров, взаимных уступок и постепенного приближения к общему взгляду на подходящий европейской системе путь развития.

2. Вторая вызывающая озабоченность сфера - «представительские проблемы». Как хорошо известно, когда сталкиваются интересы принципалов и агентов и между ними возникает информационная асимметрия, вторые чаще ставят выше собственные цели. Подобная ситуация может возникнуть между гражданами как принципалами и правительствами как агентами. Выход из этого положения заключается по большей части в сокращении асимметрии информации - становлении деятельности представителей государства прозрачной, публичной и разумно контролируемой, и в то же время граждане должны осознавать свою способность участвовать в процессе принятия решений. Эта мера нуждается в обязательстве предоставлять полную и детализованную циркуляцию информации со стороны 
правительства и в желании и способности интерпретировать доступную информацию со стороны граждан.

3. Третье затруднение связано с наличием информационной асимметрии между партнерами, вовлеченными в совместный процесс принятия решений. Различные представители могут иметь различные степени доступа к информации, необходимой для решения того или иного вопроса. Такое неравенство в распространении информации среди партнеров может быть следствием технических проблем в циркуляции информации, разных силовых позиций или намеренных стратегий, разработанных скрытыми альянсами участников. Когда происходит подобное, возникают диспропорции в процессе принятия решений, и это может отвратить некоторых партнеров от дальнейшего сотрудничества.

4. Четвертая проблема касается необходимости наличия соглашений (эксплицитных или подразумеваемых) насчет распределения переменных. Каждый субъект - в нашем случае каждое национальное государство - должен видеть, какие издержки и выгоды может нести это партнерство. Также от партнеров требуется соглашение об относительной доле затрат и выгод от принятых решений. Очевидно, что если распределение преимуществ (как и издержек и рисков) направлено против некоторых участников, достичь совместно принятых решений будет сложно.

Учитывая ключевую роль, которую играет Совет Европы в процессе принятия решений в ЕС, крайне важно бороться с этими проблемами с особым усердием. Провал в достижении сбалансированного подхода ослабит восприятие демократии и подорвет доверие к европейским институтам. С другой стороны, удачное решение этих проблем сможет помочь выстроить сотруднические отношения в рамках Европейского совета, укрепить общественное доверие и уменьшить враждебность стран-участниц по отношению к наделенным полномочиями институтам Европейского союза.

Перевод с английского студенток ФГП МГУ имени М. В. Ломоносова А. Айвазовой, К. Лиджиевой, В. Ольховской

\section{Литература}

Caffè F. In Difesa del Welfare State. Florence : Rosenberg \& Sellier, 1986.

Castell M. End of Millennium. Oxford : Blackwell, 2000.

Cooper R. The Breaking of Nations: Order and Chaos in the Twenty-First Century. London : Atlantic Books, 2003.

Eatwell J. The Theory of Value and the Foundations of Economic Policy, paper. In Memoriam: Pierangelo Garegnani. Roma Tre University 24 February. Roma, 2012.

Eichengreen B. The Break-Up of the Euro Area. NBER working paper. 2007. No. 13393.

Jachtenfuchs M. Democracy and Governance in the European Union. European Integration Online Papers (EIoP). 1997. No. 2.

Smith G., Naìm M. Altered States. Globalization, Sovereignty and Governance. Ottawa : International Development Research Centre, 2000.

Stiglitz J. Globalization and the Economic Role of the State in the New Millennium // Industrial and Corporate Change. 2003. Vol. 1. Pp. 3-26. 